\title{
Evidence for the involvement of ACC deaminase from Pseudomonas putida UW4 in the biocontrol of pine wilt disease caused by Bursaphelenchus xylophilus
}

\author{
Francisco X. Nascimento • Cláudia S. L. Vicente • Pedro Barbosa • \\ Margarida Espada $\cdot$ Bernard R. Glick $\cdot$ Manuel Mota $\cdot$ Solange Oliveira
}

Received: 13 June 2012/ Accepted: 28 November 2012

(C) International Organization for Biological Control (IOBC) 2012

\begin{abstract}
Pine wilt disease, caused by the nematode Bursaphelenchus xylophilus, is responsible for devastation of pine forests worldwide. Until now, there are no effective ways of dealing with this serious threat. The use of 1-aminocyclopropane-1-carboxylate (ACC) deaminase (encoded by the $a c d S$ gene)-producing plant growth-promoting bacteria has been shown to be a useful strategy to reduce the damage due to biotic and abiotic stresses. Pinus pinaster seedlings inoculated with the ACC deaminase-producing bacterium Pseudomonas putida strain UW4 showed an increased root and shoot development and reduction of B. xylophilus induced symptoms. In contrast, a $P$. putida UW4 acdS mutant was unable to promote pine seedling growth or
\end{abstract}

Handling Editor: Ralf Ehlers

F. X. Nascimento · C. S. L. Vicente · P. Barbosa .

M. Espada · M. Mota

NemaLab, ICAAM-Instituto de Ciências Agrárias e

Ambientais Mediterrânicas, Universidade de Évora,

Núcleo da Mitra, Apartado 94, 7002-554, Évora, Portugal

B. R. Glick

Department of Biology, University of Waterloo,

Waterloo, ON N2L 3G1, Canada

S. Oliveira $(\bowtie)$

Laboratório de Microbiologia do Solo, Departamento de Biologia, ICAAM-Instituto de Ciências Agrárias e Ambientais Mediterrânicas, Universidade de Évora, Núcleo da Mitra, Apartado 94, 7002-554 Évora, Portugal e-mail: ismo@uevora.pt to decrease B. xylophilus induced symptoms. This is the first report on the use of ACC deaminase-producing bacteria as a potential biological control agent for a tree disease, thus suggesting that the inoculation of pine seedlings grown in a tree nursery might constitute a novel strategy to obtain $B$. xylophilus resistant pine trees.

Keywords ACC deaminase - Biocontrol · Bursaphelenchus xylophilus · Pine wilt disease · Pseudomonas putida UW4 · Plant growth promoting bacteria

\section{Introduction}

Pine wilt disease (PWD) is considered to be one of the major threats affecting conifer forests and forestry economics throughout the world (Mota and Vieira 2008). This complex disease is caused by the pinewood nematode (PWN), Bursaphelenchus xylophilus, through a complex web of interactions with other biological components including PWNassociated bacteria and an insect vector, Monochamus spp., which is responsible for the PWN tree-to-tree transportation and dissemination (Vicente et al. 2012a, b). The development of PWD is also affected by abiotic factors such as temperature and water availability, which can lead to increased pine tree susceptibility to the PWN (Suzuki and Kiyohara 1978; Miki et al. 2001). 
The first report of PWD dates to 1905 in Japan (Yano 1913). Later, in the 1980s, PWD was reported in China, South Korea and Taiwan (Cheng et al. 1983; Tzean and Jan 1985a, b; Yi et al. 1989; Shin and Han 2006). In Europe, PWD was first reported in 1999 in Portugal (Mota et al. 1999). Since then, the disease has been observed throughout the Portuguese mainland and, more recently, PWD foci were found in the island of Madeira (Fonseca et al. 2012) and also in Spain (Abelleira et al. 2011). Considering the potential climate change scenarios and possible introduction points in Eastern and Northern Europe (Robinet et al. 2011), PWD may become one of the most common coniferous diseases in European forests in the near future. Although efforts to understand and control PWD have been made, to this point in time there are no effective solutions, thus, leading to huge ecological and economical losses (Dwinell 1997).

Under stressful conditions, such as a pathogen attack, plants produce the phytohormone ethylene (Hyodo 1991). If the pathogen action is intense, the autocatalytic ethylene synthesis and the consequent high levels of ethylene can be responsible for plant damage and ultimately its death (van Loon 1984). Interestingly, several authors reported an increase of ethylene levels in pine upon PWN invasion, and suggest that ethylene can play a role in PWD development (Mori and Inoue 1986; Fukuda et al. 1994; Fukuda 1997).

One potential way of limiting the damage caused by the PWN might include the inoculation of pine trees with plant growth-promoting bacteria (PGPB), which have been used for biocontrol of plant diseases (Compant et al. 2005). In this regard, one of the bacterial traits responsible for plant growth promotion, especially under stressful conditions (Glick 2005), is the activity of the enzyme 1-aminocyclopropane-1carboxylate (ACC) deaminase (encoded by the acdS gene). This enzyme cleaves the ethylene precursor, ACC, into ammonia and $\alpha$-ketobutyrate (Honma and Shimomura 1978) and thereby prevents ethylene levels in plants from rising to deleterious levels (Glick et al. 1998, 2007). The ACC deaminase-producing bacterium Pseudomonas putida UW4 has been shown to be an effective PGPB protecting several different plant hosts from a variety of stress conditions including flooding, salt, pathogens and metals (Grichko et al. 2000; Wang et al. 2000; Grichko and Glick 2001;
Cheng et al. 2007; Hao et al. 2007; Gamalero et al. 2010; Toklikishvili et al. 2010).

The use of PGPB has been shown to be a useful strategy in protecting plants against root plant parasitic nematodes (Sikora 1992; Santhi and Sivakumar 1995; Khan et al. 2008). Although PGPB molecular mechanisms responsible for enhanced plant protection are not completely understood, they often reside in nematicidal effects (antagonists). There are no reports on the use of PGPB as biological control agents against tree pathogenic nematodes, such as B. xylophilus.

This study aims to evaluate the effectiveness of the ACC deaminase-producing bacterium $P$. putida UW4 as a potential biological control agent for PWD.

\section{Methods}

Bacterial growth conditions

The bacterial strains $P$. putida UW4 (Glick et al. 1995) and $P$. putida UW4 ( $a c d S^{-}$), an $a c d S$ minus mutant of the wild-type strain ( $\mathrm{Li}$ et al. 2000), were used. The $a c d S^{-}$mutant of $P$. putida UW4 was obtained by replacing the functional acdS gene with a modified acdS gene containing a tetracycline resistance gene inserted within the coding region, through homologous recombination (Li et al. 2000).

The strains were maintained in tryptic soy broth (TSB) medium (Merck, Germany) and supplemented with tetracycline $\left(15 \mu \mathrm{g} \mathrm{ml}^{-1}\right)$ when necessary. For the inoculation assay, strains were grown in $250 \mathrm{ml}$ Erlenmeyer flasks with TSB medium at $30{ }^{\circ} \mathrm{C}$ during $24 \mathrm{~h}$. After reaching the late exponential phase, cells were collected and the optical density was measured at $540 \mathrm{~nm}$. The cell suspensions were diluted in TSB medium so that the cell concentration was $\sim 10^{8}$ CFU ml-1.

PWN growth conditions

The B. xylophilus virulent isolate "HF", collected from a symptomatic pine tree in the Setúbal region, SW Portugal, and maintained in the Nematology Lab (University of Évora, Évora, Portugal), was used in the pathogenicity test. Erlenmeyer flasks containing Botrytis cinerea growing in autoclaved barley/water 
medium (Evans 1970) for a week at $25{ }^{\circ} \mathrm{C}$, were inoculated with the PWN. Seven days after PWN feeding and reproduction, nematodes were collected by separation over a $24 \mathrm{~h}$ period in a plastic tray (Whitehead and Hemming 1965) followed by $6 \mathrm{~h}$ in a Baermann funnel (Christie and Perry 1951). A suspension of about 500 nematodes (mixed stages) was prepared for the inoculation assay.

\section{Inoculation assay in Pinus pinaster}

Three-month-old $P$. pinaster (maritime pine) seedlings, growing on non-sterilized soil, obtained from a nursery (Alfredo Moreira da Silva e Filhos, Lda., Porto, Portugal), were inoculated with wild-type P. putida UW4 or $P$. putida UW4 ( $\left.a c d S^{-}\right)$strains. Each seedling was inoculated with $5 \mathrm{ml}$ of a bacterial suspension applied to the root system. One week after bacterial inoculation, pine seedlings were inoculated with the Portuguese PWN virulent isolate "HF". One milliliter of a nematode suspension (approximately 500 nematodes, mixed stages, in distilled water) was inoculated in the stem of the pine seedlings following the method of Futai and Furuno (1979). Briefly, a small wound $(3-5 \mathrm{~mm})$ was made on the pine stem using a sterilized scalpel, and sterilized cotton was placed over the wound and fixed with Parafilm ${ }^{\mathrm{TM}}$, the cotton was subsequently drenched with the PWN suspension.

In addition to the bacterial treatments, two controls were used: a negative control (no bacteria inoculation, stem inoculation with sterile water) and a positive control (no bacteria inoculation, stem inoculation with PWN suspension). The experimental trial was conducted in a growth chamber under controlled conditions (average temperature of $24^{\circ} \pm 2{ }^{\circ} \mathrm{C}, 80 \%$ humidity, $14 \mathrm{~h}$ photoperiod). The seedlings were watered once per week with $100 \mathrm{ml}$ sterilized water. A total of 15 pine seedlings were used per each treatment. The assay was conducted as a randomized block design.

One month after nematode inoculation, pine seedlings were harvested and the disease symptomatology was assessed and categorized as described by $\mathrm{Li}$ (2007). Disease incidence was calculated according to Fang (1998). Pine seedling shoots were separated from the roots and shoot fresh weight was immediately measured. Posteriorly, the shoot was divided in smaller parts for the extraction of living nematodes following the method described by Whitehead and Hemming (1965) and Penas et al. (2002). Pine seedling roots were washed and dried for $24 \mathrm{~h}$ at $60^{\circ} \mathrm{C}$ and the root dry weight was recorded.

Nematicidal activity assay

The $P$. putida UW4 strain was tested for nematicidal activity against $B$. xylophilus by the methods described by Samaliev et al. (2000) and Ali et al. (2002). Bursaphelenchus xylophilus "HF" culture was used for the nematicidal assays. Nematodes were previously surface sterilized following the method described by Han et al. (2003).

Pseudomonas putida UW4 was grown in TSB medium (overnight at $28{ }^{\circ} \mathrm{C}$ and $120 \mathrm{rpm}$ ) and centrifuged at $1,000 \times g$ for $20 \mathrm{~min}$. The supernatant was collected and filtered using a $0.22 \mu \mathrm{m}$ filter in order to obtain a cell-free culture filtrate (Ali et al. 2002).

The pellet obtained with $P$. putida UW4 was used following the procedure developed by Samaliev et al. (2000). The pellet was re-suspended in $570 \mu \mathrm{l}$ of $10 \mathrm{mM}$ Tris $\mathrm{pH}$ 8.0, $1 \mathrm{mM}$ EDTA and cells lysed by addition of $30 \mu \mathrm{l}$ of $10 \%$ SDS (sodium dodecyl sulfate). After incubation at $37^{\circ} \mathrm{C}$ for $1 \mathrm{~h}$, the suspension was centrifuged at $15,000 \times g$ for $20 \mathrm{~min}$, and the supernatant collected for further use.

Three treatments were prepared to test the nematicidal activity of $P$. putida UW4: (1) nematodes in the presence of $P$. putida UW4 cell-free culture filtrate, (2) nematodes in the presence of $P$. putida UW4 supernatant of lysed cells, and (3) control (TE and $10 \%$ SDS). Each treatment was repeated three times using 15 nematodes for each test. An observation on the number of dead nematodes was conducted during the following 24 and $48 \mathrm{~h}$.

\section{Statistical analysis}

The data obtained from the inoculation assay was examined by ANOVA, and means were compared by Tukey's HSD test. Statistical analysis was carried out using SPSS statistics V.17 (SPSS Inc., IBM Company). 


\section{Results}

Pinus pinaster seedlings inoculated with nematodes only showed the expected symptoms of PWD (data not shown). The previous inoculation of $P$. pinaster seedlings with wild-type $P$. putida UW4 led to a significant reduction of PWD symptoms development (Table 1). Interestingly, pine seedlings inoculated with $P$. putida UW4 (acd $S^{-}$) were affected by the disease to the same extent as seedlings inoculated with only PWN (Table 1). That is, the $a c d S^{-}$mutant did not protect pine seedlings against PWD. No disease symptoms were observed in the negative control seedlings.

The shoot fresh weight of pine seedlings inoculated with $P$. putida UW4 was significantly higher when compared to the positive control or $P$. putida UW4 $\left(\operatorname{acd} S^{-}\right)$inoculated plants $\left(F_{(3,56)}=33.852, p<0.001\right)$ (Fig. 1). Regardless of the nematode inoculation, $P$. putida UW4 inoculated seedlings showed approximately the same shoot fresh weight as the negative control seedlings. No significant differences were found between seedlings inoculated with $P$. putida UW4 $\left(a c d S^{-}\right)$and seedlings inoculated only with the PWN (Fig. 1).

The inoculation of pine seedlings with P. putida UW4 lead to an increased level of seedling root development. The root dry weight of wild-type $P$. putida UW4 inoculated seedlings was also significantly higher when compared to all other treatments $\left(F_{(3,56)}=22.198\right.$, $p<0.001$ ) (Fig. 2). There were no significant

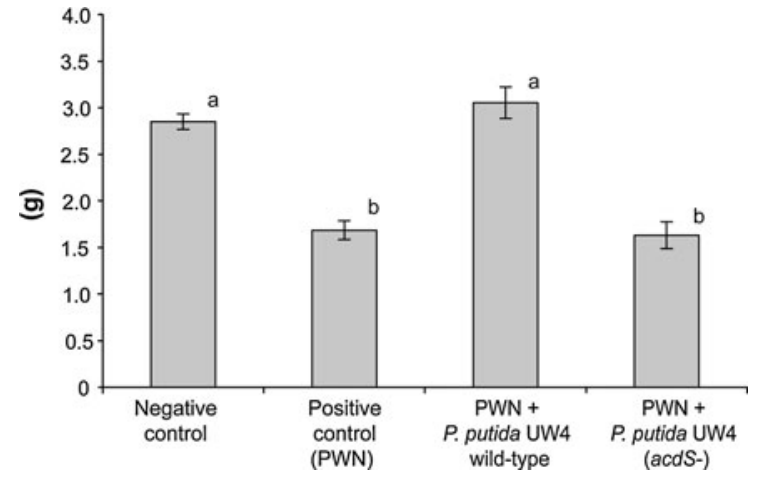

Fig. 1 Shoot fresh weight of $P$. pinaster seedlings, one month after PWN inoculation. Data correspond to the mean and SE values of 15 seedlings per treatment. Different letters $(a, b)$ correspond to statistical significant differences $(p<0.001)$

differences between the root dry weight of the positive control or $P$. putida UW4 ( $a c d S^{-}$) inoculated seedlings. As expected, the negative control seedlings had a higher dry weight than the positive control seedlings.

Interestingly, the number of living nematodes recovered was lower in seedlings inoculated with wild-type $P$. putida UW4 (Table 1) compared to the high number of living nematodes recovered from the positive control or from $P$. putida UW4 $\left(a c d S^{-}\right)$ inoculated seedlings. Nevertheless, in vitro assays indicated that $P$. putida UW4 has no nematicidal effects towards $B$. xylophilus. Nematode viability was not affected by the presence of either P. putida UW4 cell-free culture filtrate or cell lysis supernatant.

Table 1 Disease symptomatology following the inoculation of $P$. pinaster seedlings with the nematode B. xylophilus and with either wild-type $P$. putida $\mathrm{UW4}$ or the mutant $P$. putida $\mathrm{UW4}\left(\operatorname{acd} S^{-}\right)$

\begin{tabular}{|c|c|c|c|c|c|}
\hline Treatment & $\begin{array}{l}\text { Average } \\
\text { symptom stage }\end{array}$ & $\begin{array}{l}\text { Disease } \\
\text { incidence index }\end{array}$ & $\begin{array}{l}\text { Average shoot } \\
\text { growth }^{\mathrm{a}}(\%)\end{array}$ & $\begin{array}{l}\text { Average root } \\
\text { growth }^{\mathrm{a}}(\%)\end{array}$ & $\begin{array}{l}\text { Estimated number of living } \\
\text { nematodes }^{\text {b }}\end{array}$ \\
\hline Negative control & 1 & 0.11 & 0 & 0 & 0 \\
\hline $\begin{array}{l}\text { PWN (positive } \\
\text { control) }\end{array}$ & 3 & 0.82 & $-41 \pm 4$ & $-35 \pm 6$ & 702 \\
\hline $\begin{array}{l}\mathrm{PWN}+P \cdot \text { putida } \\
\text { UW4 }\end{array}$ & 2 & 0.56 & $7 \pm 6$ & $61 \pm 13$ & 160 \\
\hline $\begin{array}{l}\mathrm{PWN}+P \cdot \text { putida } \\
\text { UW4 }\left(\text { acd } S^{-}\right)\end{array}$ & 3 & 0.76 & $-43 \pm 5$ & $-17 \pm 4$ & 570 \\
\hline
\end{tabular}

Disease stage symptoms (Li 2007): 0, no needle discoloration; 1, only needles around the inoculated place are yellowish, needles in the other part are green; 2, needles in the upper and lower part of the inoculation spot are brown yellowish, and needles in the top of the tree are greyish green; 3, needles in the upper and lower part of the inoculation spot are brown yellowish, and needles in the top are yellowish green; 4, all needles of the plant are yellowish brown; 5, all needles are brown

${ }^{\text {a }}$ Compared to the negative control. The values represent the average $\pm \mathrm{SE}$

b Total number of living nematodes extracted from all pine seedlings belonging to each treatment 


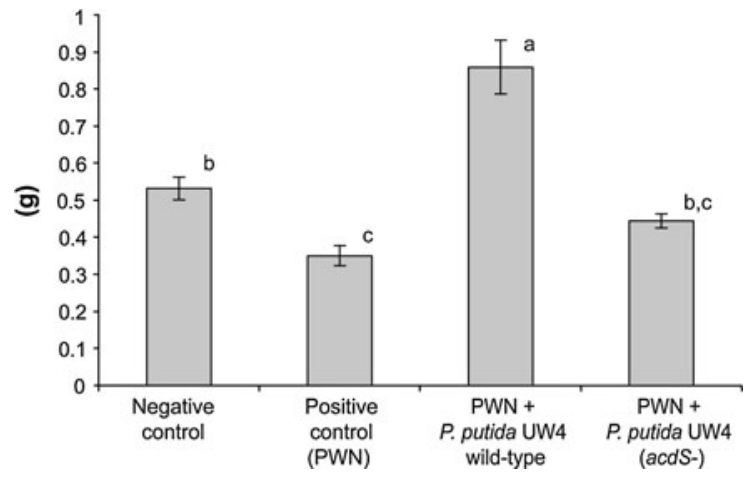

Fig. 2 Root dry weight of $P$. pinaster seedlings, one month after PWN inoculation. Data correspond to the mean and SE values of 15 seedlings per treatment. Different letters $(a, b, c)$ correspond to statistical significant differences $(p<0.05)$

\section{Discussion}

The results presented here indicate that, by producing ACC deaminase, wild-type $P$. putida UW4 acts indirectly as a biological control agent, decreasing PWD development. It has been previously demonstrated that ethylene production increases in pine trees during PWN invasion, suggesting that increased ethylene levels are, at least partially, responsible for the development of PWD symptoms (Mori and Inoue 1986; Fukuda et al. 1994; Fukuda 1997). The data presented here are consistent with the possibility that, through ACC deaminase production, $P$. putida UW4 reduces the deleterious ethylene levels in pine seedlings induced by PWN invasion, thereby decreasing the disease severity and progression. This idea is supported by the fact that $P$. putida UW4 $\left(a c d S^{-}\right)$, with its acdS gene interrupted, is unable to decrease PWD symptoms or to induce any beneficial effect on the PWN infected seedlings.

Similar results have been obtained with castor bean and tomato plants infected by Agrobacterium tumefaciens. While P. putida UW4 was able to decrease crown gall formation and subsequent damage and loss of plant biomass, the acdS knockout mutant had no significant impact on protecting tomato plants from the A. tumefaciens infection (Hao et al. 2007; Toklikishvili et al. 2010). These results suggest that ACC deaminase activity, and the consequent lowering of deleterious plant ethylene levels, is the mechanism responsible for $P$. putida UW4 plant growth promotion activity as well as its ability to protect plants against biotic as well as abiotic stress (Grichko et al.
2000; Wang et al. 2000; Cheng et al. 2007; Glick et al. 2007; Hao et al. 2007; Gamalero et al. 2010; Toklikishvili et al. 2010). In addition, it has been previously demonstrated that transgenic plants that express a bacterial acdS gene under the control of a root specific promoter are more resistant to pathogen induced stress as well as abiotic stress caused by salt, flooding and metals (Robison et al. 2001a, b; Grichko and Glick 2001; Grichko et al. 2000; Stearns et al. 2005; Sergeeva et al. 2006).

In this work, the PGPB P. putida UW4 successfully induced pine tree seedling growth, in the presence of the PWN. It also reduced PWD symptoms caused by the PWN. It is probable that by both reducing deleterious ethylene levels and directly promoting plant growth, $P$. putida UW4 can boost plant defense systems, thus helping pine seedlings to overcome some of the negative consequences of PWN infection. This is consistent with the low number of living nematodes recovered from $P$. putida UW4 inoculated plants. Moreover, $P$. putida UW4 showed no nematicidal effects against $B$. xylophilus, suggesting that it has no direct effect on the observed decrease of the nematode population.

Further studies may allow the improvement of the biocontrol effect of $P$. putida UW4 in PWD, including its co-inoculation with other microorganisms namely arbuscular mycorrhiza. Synergistic interactions between $P$. putida UW4 and the arbuscular mycorrhizal fungus Gigaspora rosea, that positively affected cucumber plant growth, have been described (Gamalero et al. 2008, 2010).

Altogether, the results obtained suggest that the inoculation of pine seedlings with ACC deaminaseproducing PGPB in a nursery system may be used as part of a strategy to obtain PWN resistant pine trees. Moreover, since temperature and water availability stresses also play a role in disease development and expression, the use of these bacteria may prove useful to reduce both abiotic and PWN induced stress, leading to an increased level of plant protection. This is the first report describing the use of an ACC deaminase-producing bacterium as a biological control agent for PWD.

Acknowledgments This work was supported by the European Project REPHRAME-development of improved methods for detection, control and eradication of pine wood nematode in support of EU Plant Health Policy, European Union Seventh Framework Programme FP7-KBBE-2010-4 and the European 
Project BioReGent-Biocontrol and Bioremediation Agents and their role in Agriculture and Forest Health, European Union Seventh Framework Programme FP7-PEOPLE-2009-IRSES (grant agreement no. 247669); and FEDER Funds through the Operational Programme for Competitiveness FactorsCOMPETE and National Funds through FCT-Foundation for Science and Technology under the Strategic Project PEst-C/ AGR/UI0115/2011.

\section{References}

Abelleira A, Picoaga A, Mansilla JP, Aguin O (2011) Detection of Bursaphelenchus xylophilus, causal agent of pine wilt disease on Pinus pinaster in Northwestern Spain. Plant Dis 95:776

Ali NI, Siddiqui IA, Shaukat SS, Zaki MJ (2002) Nematicidal activity of some strains of Pseudomonas spp. Soil Biol Biochem 34:1051-1058

Cheng HR, Lin M, Li W, Fang Z (1983) The occurrence of a pine wilting disease caused by a nematode found in Nanjing. For Pest Dis 4:1-5

Cheng Z, Park E, Glick BR (2007) 1-Aminocyclopropane-1carboxylate (ACC) deaminase from Pseudomonas putida UW4 facilitates the growth of canola in the presence of salt. Can J Microbiol 53:912-918

Christie JR, Perry VG (1951) Removing nematodes from soil. Proc Helminthol Soc Wash 18:106-108

Compant S, Duffy B, Nowak J, Clément C, Barka EA (2005) Use of plant growth-promoting bacteria for biocontrol of plant diseases: principles, mechanisms of action, and future prospects. Appl Environ Microbiol 71:4951-4959

Dwinell LD (1997) The pinewood nematode: regulation and mitigation. Annu Rev Phytopathol 35:153-166

Evans AAF (1970) Mass culture of mycophagous nematodes. J Nematol 2:99-100

Fang ZD (1998) Methods in research of plant disease. Chinese Agricultural Publishing House, Beijing, China

Fonseca L, Cardoso JMS, Lopes A, Pestana M, Abreu F, Nunes N, Mota M, Abrantes I (2012) The pinewood nematode, Bursaphelenchus xylophilus, in Madeira Island. Helminthologia 49:96-103

Fukuda K (1997) Physiological process of the symptom development and resistance mechanism in pine wilt disease. J For Res 2:171-181

Fukuda K, Hogetsu T, Suzuki K (1994) Ethylene production during symptom development of pine-wilt disease. Eur $\mathrm{J}$ For Pathol 24:193-202

Futai K, Furuno T (1979) The variety of resistances among pinespecies to pine wood nematode, Bursaphelenchus lignicolus. Bull Kyoto Univ For 51:23-36

Gamalero E, Berta G, Massa N, Glick BR, Lingua G (2008) Synergistic interactions between the ACC deaminaseproducing bacterium Pseudomonas putida UW4 and the AM fungus Gigaspora rosea positively affect cucumber plant growth. FEMS Microbiol Ecol 64:459-467

Gamalero E, Berta G, Massa N, Glick BR, Lingua G (2010) Interactions between Pseudomonas putida UW4 and Gigaspora rosea BEG9 and their consequences for the growth of cucumber under salt-stress conditions. J Appl Microbiol 108:236-245

Glick BR (2005) Modulation of plant ethylene levels by the bacterial enzyme ACC deaminase. FEMS Microbiol Lett 251:1-7

Glick BR, Karaturovíc D, Newell P (1995) A novel procedure for rapid isolation of plant growth-promoting rhizobacteria. Can J Microbiol 41:533-536

Glick BR, Penrose DM, Li JP (1998) A model for the lowering of plant ethylene concentrations by plant growth-promoting bacteria. J Theor Biol 190:63-68

Glick BR, Cheng Z, Czarny J, Duan J (2007) Promotion of plant growth by ACC deaminase-producing soil bacteria. Eur J Plant Pathol 119:329-339

Grichko VP, Glick BR (2001) Flooding tolerance of transgenic tomato plants expressing the bacterial enzyme ACC deaminase controlled by the $35 \mathrm{~S}$, rolD or PRB-1b promoter. Plant Physiol Biochem 39:19-25

Grichko VP, Filby B, Glick BR (2000) Increased ability of transgenic plants expressing the bacterial enzyme ACC deaminase to accumulate $\mathrm{Cd}, \mathrm{Co}, \mathrm{Cu}, \mathrm{Ni}, \mathrm{Pb}$, and $\mathrm{Zn}$. J Biotechnol 81:45-53

Han Z, Hong Y, Zhao B (2003) A study on pathogenicity of bacteria carried by pine wood nematodes. J Phytopathol 151:683-689

Hao Y, Charles TC, Glick BR (2007) ACC deaminase from plant growth-promoting bacteria affects crown gall development. Can J Microbiol 53:1291-1299

Honma M, Shimomura T (1978) Metabolism of 1-aminocyclopropane-1-carboxylic acid. Agric Biol Chem Tokyo 42:1825-1831

Hyodo H (1991) Stress/wound ethylene. In: Mattoo AK, Shuttle JC (eds) The plant hormone ethylene. CRC Press, Boca Raton, USA, pp 65-80

Khan Z, Kim SG, Jeon YH, Khan HU, Son SH, Kim YH (2008) A plant growth promoting rhizobacterium, Paenibacillus polymyxa strain GBR-1, suppresses root-knot nematode. Bioresour Technol 99:3016-3023

Li H (2007) Identification and pathogenicity of Bursaphelenchus species (Nematoda: Parasitaphelenchidae). PhD Thesis, University of Ghent, Belgium

Li J, Ovakim DH, Charles TC, Glick BR (2000) An ACC deaminase minus mutant of Enterobacter cloacae UW4 no longer promotes root elongation. Curr Microbiol 41: 101-105

Miki N, Sakamoto K, Nishimoto T, Yoshikawa K, Hada Y (2001) Relationship between the incidence of pine wilt disease and the drainage area. J For Res 6:181-186

Mori T, Inoue T (1986) Pinewood nematode-induced ethylene production in pine stems and cellulase as an inducer. $\mathrm{J} \mathrm{Jpn}$ For Soc 68:43-50

Mota M, Vieira P (2008) Pine wilt disease: a worldwide threat to forest ecosystems. Springer, Dordrecht, The Netherlands

Mota M, Braasch H, Bravo MA, Penas AC, Burgermeister W, Metge K, Sousa E (1999) First report of Bursaphelenchus xylophilus in Portugal and in Europe. Nematology 1: 727-734

Penas AC, Dias LS, Mota M (2002) Precision and selection of extraction methods of aphelenchid nematodes from maritime pine wood, Pinus pinaster L. J Nematol 34:62-65 
Robinet C, Opstal NV, Baker R, Roques A (2011) Applying a spread model to identify the entry points from which the pinewood nematode, the vector of pine wilt disease, would spread most rapidly across Europe. Biol Invasions 13:2981-2995

Robison MM, Griffith M, Pauls KP, Glick BR (2001a) Dual role of ethylene in susceptibility of tomato to Verticillium wilt. J Phytopathol 149:385-388

Robison MM, Shah S, Tamot B, Pauls KP, Moffatt BA, Glick BR (2001b) Reduced symptoms of Verticillium wilt in transgenic tomato expressing a bacterial ACC deaminase. Mol Plant Pathol 2:135-145

Samaliev HY, Andreoglou FI, Elawad SA, Hague NGM, Gowen SR (2000) The nematicidal effects of the bacteria Pseudomonas oryzihabitans and Xenorhabdus nematophilus on the root-knot nematode Meloidogyne javanica. Nematology 2:507-514

Santhi A, Sivakumar V (1995) Biocontrol potential of Pseudomonas yuorescens (Migula) against root-knot nematode, Meloidogyne incognita (Kofoid and White, 1919) Chitwood, 1949 on tomato. J Biol Control 9:113-115

Sergeeva E, Shah S, Glick BR (2006) Growth of transgenic canola (Brassica napus) expressing a bacterial 1-aminocyclopropane-1-carboxylate (ACC) deaminase gene on high concentrations of salt. World J Microbiol Biotechnol 22:277-282

Shin S, Han H (Oct 2006) Current status on research and management of pine wilt disease in Korea. In: Current status on research and management of pine wilt disease, international symposium, 20 Oct 2006. Korea Forest Research Institute, Seoul, Korea, pp 31-44

Sikora RA (1992) Management of the antagonistic potential in agricultural ecosystems for the biological control of plant parasitic nematodes. Annu Rev Phytopathol 30:245-270

Stearns JC, Shah S, Dixon DG, Greenberg BM, Glick BR (2005) Tolerance of transgenic canola expressing 1-aminocyclopropane-carboxylic acid deaminase to growth inhibition by nickel. Plant Physiol Biochem 43:701-708

Suzuki K, Kiyohara T (1978) Influence of water stress on development of pine wilting disease caused by Bursaphelenchus lignicolus. Eur J For Pathol 8:97-107

Toklikishvili N, Dandurishvili N, Vainstein A, Tediashvili M, Giorgobiani N, Lurie S, Szegedi E, Glick BR, Chernin L (2010) Inhibitory effect of ACC deaminase-producing bacteria on crown gall formation in tomato plants infected by Agrobacterium tumefaciens or A. vitis. Plant Pathol 59:1023-1030

Tzean S, Jan S (1985a) The occurrence of pinewood nematode, Bursaphelenchus xylophilus, in Taiwan. In: Proceedings of the 6th ROC symposium of electron microscopy, pp 38-39

Tzean S, Jan S (1985b) Pine wilt disease caused by pinewood nematode (Bursaphelenchus xylophilus) and its occurrence in Taiwan. Phytopathol Entomol NTU 12:1-19

van Loon LC (1984) Regulation of pathogenesis and symptom expression in diseased plants by ethylene. In: Fuchs Y, Chalutz E (eds) Ethylene: biochemical, physiological and applied aspects. Martinus Nijhoff/Dr W. Junk, The Hague, The Netherlands, pp 171-180

Vicente CSL, Espada M, Vieira P, Mota M (2012a) Pine wilt disease: a threat to European forestry. Eur J Plant Pathol 133:89-99

Vicente CSL, Nascimento FX, Espada M, Barbosa P, Mota M, Glick BR, Oliveira S (2012b) Characterization of bacteria associated with pinewood nematode Bursaphelenchus $x y$ lophilus. PLoS ONE 7:e46661

Wang CX, Knill E, Glick BR, Defago G (2000) Effect of transferring 1-aminocyclopropane-1-carboxylic acid (ACC) deaminase genes into Pseudomonas fluorescens strain CHA0 and its gacA derivative CHA96 on their growth-promoting and disease-suppressive capacities. Can J Microbiol 46:898-907

Whitehead AG, Hemming JR (1965) A comparison of some quantitative methods of extracting small vermiform nematodes from soil. Ann Appl Biol 55:25-38

Yano M (1913) Investigation on the cause of pine mortality in Nagasaki Prefecture. Sanrinkoho 4:1-14 (in Japanese)

Yi C, Byun B, Park J, Yang S, Chang K (1989) First finding of the pine wood nematode, Bursaphelenchus xylophilus (Steiner et Buhrer) Nickle and its insect vector in Korea. Res Rep For Res Inst Seoul 38:141-149

\section{Author Biographies}

Francisco X. Nascimento focuses mainly on beneficial bacteria, including bacteria used in the biocontrol of pine wilt disease caused by the pinewood nematode (PWN), Bursaphelenchus xylophilus, as well as rhizobia, together with S. Oliveira and B. Glick.

Cláudia S. L. Vicente is a Postdoctoral Fellow investigating bacteria associated with the pinewood nematode including a possible role of bacteria in pine wilt disease.

Pedro Barbosa research is focused on phytoparasite nematodes, including the use of phytochemicals for controlling PWN.

Margarida Espada is a $\mathrm{PhD}$ student investigating the genetics of PWN.

Bernard R. Glick is a full Professor of molecular biotechnology and has expertise in the biochemical and genetic mechanisms used by plant growth-promoting bacteria.

Manuel Mota is the Leader of the Portuguese team that detected the PWN, for the first time, in Portugal and in Europe, and since then has been investigating B. xylophilus.

Solange Oliveira has focused mainly on the molecular biology of rhizobia as well as other plant beneficial bacteria. 